\title{
Relationship of Tumor Thickness with Neck Node Metastasis in Buccal Squamous Cell Carcinoma: An Experience at a Tertiary Care Hospital
}

\author{
Sadaf Qadeer Ahmed ${ }^{1}$ Montasir Junaid ${ }^{2}$ Sohail Awan ${ }^{3} \quad$ Moaz M. Choudhary ${ }^{4}$ Maliha Kazi ${ }^{5}$ \\ Aria Masoom ${ }^{6}$ Hareem Usman Khan ${ }^{7}$
}

${ }^{1}$ Department of Otorhinolaryngology, Sir Syed College of Medical Sciences for Girls Ringgold Standard Institution, Karachi, Pakistan

2 Department of Otorhinolaryngology, Jinnah Medical and Dental College Ringgold Standard Institution, Karachi, Pakistan

${ }^{3}$ Department of Otorhinolaryngology, Aga Khan University Ringgold

Address for correspondence Sadaf Qadeer Ahmed, FCPS, Assistant Professor, Department of Otorhinolaryngology, Sir Syed College of Medical Sciences for Girls, Korangi Road, Karachi 74800, Pakistan (e-mail: sadaf.qkhan@gmail.com; sadaf_q1@hotmail.com).

Standard Institution, Karachi, Pakistan

${ }^{4}$ Department of Medicine, Aga Khan University Ringgold Standard

Institution, Karachi, Pakistan

${ }^{5}$ Department of Otorhinolaryngology, Manchester Royal Infirmary, Manchester, United Kingdom

${ }^{6}$ Department of Otorhinolaryngology, Bolan Medical College

Ringgold Standard Institution, Quetta, Pakistan

${ }^{7}$ Department of Medicine, Shifa College of Medicine Ringgold

Standard Institution, Islamabad, Pakistan

Int Arch Otorhinolaryngol 2017;21:265-269.

\begin{abstract}
Introduction Squamous cell carcinoma is the most common malignancy of the head and neck, with the buccal mucosa being the most common site involved. Early locoregional metastasis is a hallmark of this disease, and early stage tumors may harbor metastatic nodes that are occult. Certain parameters can help identify high-risk patients for whom the pattern of occult nodal metastasis can be predicted. Tumor thickness is one such objective parameter.

Objective To determine the relationship of tumor thickness with neck node metastasis in squamous cell carcinoma of the buccal mucosa.

Methods A retrospective chart review of 102 patients with biopsy-proven squamous cell carcinoma of the buccal mucosa with $\mathrm{N}_{0}$ Necks was performed. All patients underwent tumor resection with neck dissection, and the tumor thickness was measured. Univariate and multivariate analyses were performed.

Results A total of 102 patients, of which $73.53 \%$ were males and $26.47 \%$ were females. The mean age of the patients was $49.3 \pm 11.1$ years. It was found that the risk of neck node metastasis in buccal squamous cell carcinoma increases 35.5 times for a tumor thickness $\geq 2 \mathrm{~mm}$, and the risk of neck node metastasis in buccal squamous cell

Keywords

- buccal mucosa

- squamous cell carcinoma

- metastasis carcinoma decreases by 0.58 times for each centimeter decrease in tumor size, while the rate of occult neck lymph node metastasis was found to be $37 \%$.

Conclusion We conclude that tumor thickness is significantly related with neck nodal metastasis in buccal squamous cell carcinoma, considering the age of the patient and the size of the tumor.
\end{abstract}

received

July 23, 2016

accepted

January 15, 2017

published online

February 21, 2017
DOI https://doi.org/

10.1055/s-0037-1599061. ISSN 1809-9777.
Copyright $(2017$ by Thieme Revinter

Publicações Ltda, Rio de Janeiro, Brazil
License terms

(c) (i) $\ominus$ (\$) 


\section{Introduction}

Oral cancer is the most frequent head and neck malignancy worldwide. According to the World Health Organization (WHO), oral cancer rates are expected to increase from 10 million cases in 2000 to 15 million cases in $2020 .{ }^{1}$ There is global and regional variation in the incidence of oral cancers due to local geographical, biological, dietary and environmental factors. ${ }^{2}$ Needless to say, the majority of these cancers are squamous cell carcinomas. Among the subsites of the oral cavity, the buccal mucosa is one of the most common areas involved, accounting for $\sim 50 \%$ of all oral cavity tumors. Buccal mucosa involvement is due to people's frequent consumption of pan, betel nut, tobacco, and niswaar. ${ }^{2}$

Squamous cell carcinoma of the buccal mucosa is an aggressive malignancy, with a greater propensity for invasion into the surrounding tissues and metastasis to the cervical lymph nodes. ${ }^{3}$ The involvement of the cervical lymph nodes greatly impacts the treatment protocol and the prognosis of squamous cell carcinoma of the buccal mucosa. ${ }^{4}$

Advanced stage tumors with clinical or radiological evidence of neck nodes warrant a definitive neck dissection. ${ }^{5}$ It is the early stage tumors without any clinical or radiological evidence whose management remains controversial. ${ }^{6-8}$ They may harbor disease (36-42\%), as reported in the literature $;{ }^{9-11}$ however, at the same time, performing an unnecessary neck dissection can lead to avoidable complications and gruesome outcomes.

Certain parameters can help in identifying high-risk patients, for whom an elective neck dissection is justifiable. $^{12-15}$ Tumor thickness is one such objective parameter, and it is assessed in various studies. The increasing depth of invasion and the microvascular proliferation caused by the neoplastic growth might determine the proximity to blood vessels and lymphatics, thus facilitating the tumor's ability to metastasize. ${ }^{4,5,16}$

Our experience in using tumor thickness as a predictor for identifying occult neck nodal metastases in clinically and radiologically negative necks in squamous cell carcinoma of the buccal mucosa is described as follows.

\section{Objective}

To determine the relationship of the tumor thickness with the neck node metastasis in squamous cell carcinoma of the buccal mucosa.

\section{Materials and Methods}

After taking approval from the ethical review committee of the Aga Khan University \& Hospital, the study was initiated. This study was a retrospective chart review of patients treated for squamous cell carcinoma of the buccal mucosa at the Department of Otolaryngology - Head and Neck Surgery of the Aga Khan University \& Hospital from May 1st 2008 to May 31st 2013. All patients, irrespective of their

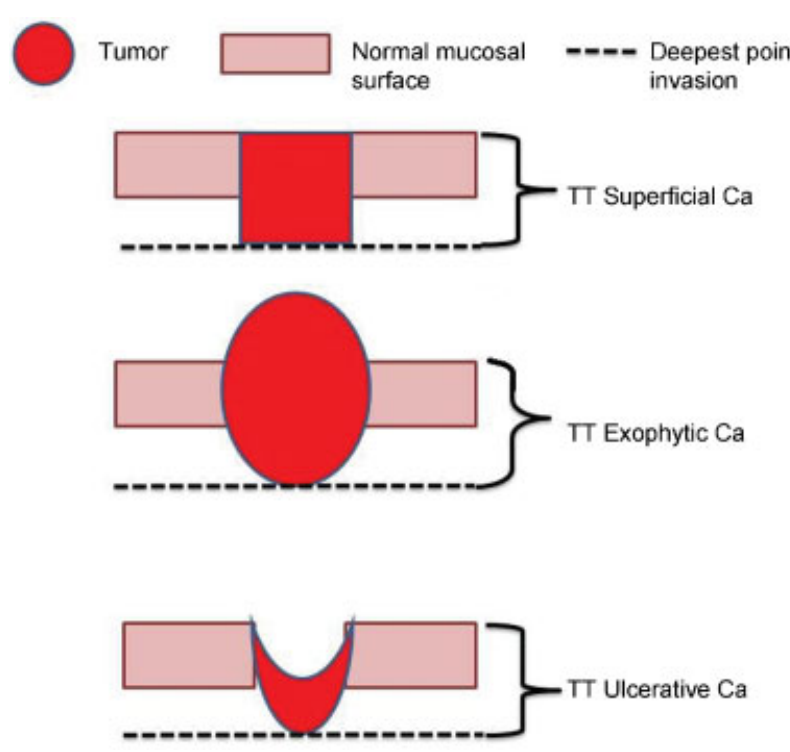

Fig. 1 Tumor thickness (TT) measurement.

age, gender, race or tumor stage were recruited. A total of 102 patients were recruited in the study. Data were recorded using a structured questionnaire. Patients with a biopsyproven squamous cell carcinoma of the buccal mucosa without any clinical or radiological signs of cervical node metastasis were included in the study. Patients who had previously received treatment and patients who had recurrence were excluded. All the patients involved in the study underwent wide local excisions of the buccal mucosa lesion along with ipsilateral functional neck dissection. The excised specimens were sent routinely to the Histopathology Department of the Aga Khan University \& Hospital for assessment.

Data were collected from the assessment of patient charts and the review of histopathology reports. The variables assessed were age, gender, addiction, T-stage of the tumor and tumor thickness. All tumor margins were negative for tumor involvement in the final histopathology. The presence or absence of occult cervical lymph node metastasis was also extracted from the final histopathology report.

Tumor thickness, which is the objective parameter of the depth of invasion, was measured by a senior histopathologist from the surface of the tumor to the deepest point of the tumor invasion, as proposed by Moore et $\mathrm{al}^{17}$ ( - Fig. 1).

All the variables mentioned before were analyzed for their association with the presence of occult cervical lymph nodes metastasis on the final histopathology.

\section{Statistical Analysis}

Data were analyzed using the Statistical Package for Social Sciences (SPSS, SPSS Inc., Chicago, IL, USA) software, version 19.0. Continuous variables were expressed as mean \pm standard deviations (SDs), while discrete variables were shown as frequency (\%). A univariate analysis was conducted to explore the association of each variable with the outcome. Multivariable logistic regression was applied to estimate the odds ratio (OR) for the presence of occult cervical lymph 
Table 1 Univariate analysis $(n=102)$

\begin{tabular}{|l|l|l|}
\hline & $\begin{array}{l}\text { Unadjusted OR } \\
(\mathbf{9 5 \% C l})\end{array}$ & $p$ value \\
\hline Tumor thickness (in $\mathrm{mm})$ & $0.38(0.20,0.71)$ & 0.004 \\
\hline Age (years) & $1.05(1.01,1.09)$ & 0.022 \\
\hline Tumor size (in cm) & $0.59(0.46,0.78)$ & $<0.001$ \\
\hline
\end{tabular}

Abbreviations: $95 \% \mathrm{Cl}, 95 \%$ confidence interval; cm, centimeters; mm, millimeters; OR, odds ratio.

nodes metastasis adjusting for other variables. The independent variables included were tumor thickness, age and tumor size. Model adequacy was checked by Hosmer-Lemeshow test.

\section{Results}

Total 102 patients $(n=102)$ according to the eligibility criteria were included in the study; $73.53 \%$ (75) of them were male, and $26.47 \%$ (27) were female. The mean age of the patients was $49.3 \pm 11.1$ years; the mean size of the tumors was $3.5 \pm 1.8 \mathrm{~cm}$; $92.15 \%$ (94) had a history of addiction (alcohol use, cigarette smoking or chewing tobacco).

Patients were categorized according to tumor thickness $<2 \mathrm{~mm}$, or $>2 \mathrm{~mm}$. Thickness $<2 \mathrm{~mm}$ was found in $91.17 \%$ (93) of the patients, and less than 9\% had a thickness $>2 \mathrm{~mm}$. The majority of the patients had early stage tumors, that is, 34\% had stage I, and 35\% had stage II tumors; and $23 \%$ and $8 \%$ of them had stage III and IV tumors respectively. From all patients, $25.50 \%$ (26) had well-differentiated tumors, and 67.65\% (69) and 6.85\% (7) had moderately, and poorly differentiated tumors respectively. Cervical lymph node metastasis was found in $37 \%$ of the patients, and $63 \%$ of them had no signs of cervical node metastasis on the histopathology report.

The patients' age, tumor thickness and sizer were significant predictors of cervical lymph node metastasis on the univariate analysis, with a $p$ value $<0.05$ (-Table 1).

When these variables were analyzed using the multivariate regression, it was noted that the associations among age, tumor thickness and tumor size were statistically significant with cervical node metastasis (-Table 2). It was further identified that the risk of neck node metastasis in buccal squamous cell carcinoma increases 35.5 times for a

Table 2 Multivariate analysis $(n=102)$

\begin{tabular}{|l|l|l|}
\hline & Adjusted OR (95\%Cl) & $p$ value \\
\hline $\begin{array}{l}\text { Tumor thickness } \\
(\mathrm{T} \geq 2 \mathrm{~mm}) \\
\text { (Ref: } \mathrm{T}<2 \mathrm{~mm})\end{array}$ & $35.52(2.39,527.26)$ & 0.009 \\
\hline Age (years) & $1.06(1.01,1.12)$ & 0.027 \\
\hline Tumor size (in cm) & $0.58(0.40,0.82)$ & 0.002 \\
\hline
\end{tabular}

Abbreviations: $95 \% \mathrm{Cl}, 95 \%$ confidence interval; cm, centimeters; mm, millimeters; OR, odds ratio; $\mathrm{T}$, tumor thickness. tumor thickness of $\geq 2 \mathrm{~mm}$, provided the confounding variables remain constant.

With every 10 years increase in age, the risk of neck node metastasis in buccal squamous cell carcinoma increases by 1.84 times, adjusting for other variables. The risk of neck node metastasis in buccal squamous cell carcinoma decreases by 0.58 times for each centimeter decrease in tumor size. The Hosmer-Lemeshow test showed model adequacy at $p=0.417$.

\section{Discussion}

The WHO estimates the incidence of cancer is bound to increase globally, with head and neck cancers being the fifth most common malignancy. ${ }^{1}$ However, the situation in South Asia is completely different, with head and neck cancers being ranked as the most common malignancies in males, and the second most common in females. ${ }^{18}$ Maintaining consistency with the data from the western Europe and North America, the oral cavity remains the most commonly involved site; however, the buccal mucosa seems to be the most frequent subsite in our part of the world, compared with the oral tongue in the West. ${ }^{19}$ This difference in the subsite is quite expected when we take into consideration the prevalent cultural practice of chewing tobacco in South Asia. Similarly, recent local studies have also shown that squamous cell carcinoma of the buccal mucosa appears to be more aggressive compared with the other subsites of the oral cavity, ${ }^{20-22}$ which contradicts recent reports from other parts of the world. ${ }^{23}$ In our study, we also found that $92 \%$ of the patients had a history of addiction that was comparable.

It is an established fact that cervical lymph node metastasis is the most critical prognostic factor for head and neck cancers, and that has been shown in multiple studies; $3,24-26$ thus, the treatment must not only address the primary site, but should also address the cervical lymph nodes. For advanced stage tumors with clinically or radiologically positive neck nodes, the decision to perform a neck dissection is not debatable. However, the treatment of early stage tumors with no clinical or radiological evidence of metastasis to the cervical lymph nodes remains controversial. ${ }^{7,8}$ Various studies have shown the presence of occult cervical lymph node metastasis to be as high as $45 \% .{ }^{9,11}$ With the use of advanced immunohistochemical and molecular analyses of neck specimens instead of the traditional hematoxylin \& eosin (H\&E) and light microscopy, the exact incidence of occult cervical lymph nodes metastasis is believed to be higher than actually reported. ${ }^{27-29}$ Our study showed $63 \%$ of patients had cervical lymph node metastasis in the final histopathology report. Furthermore, despite the great advances in technology, none of the currently available imaging modalities is reliably able to detect the presence of occult lymph node metastasis. ${ }^{30,31}$

There have been multiple studies that identify the tumor thickness as a predictor of cervical lymph metastasis, ${ }^{12,13,25}$ but none of them showed the similar cutoff point of tumor thickness on which neck dissection should be performed. For instance, Mishra et al, in their study of 176 patients with buccal squamous cell carcinoma, found $4 \mathrm{~mm}$ tumor 
thickness to be a significant predictor of lymph node metastasis. $^{32}$ On the other hand, Urist et al described a series of 89 patients with squamous cell carcinoma of the buccal mucosa and showed that greater than $6 \mathrm{~mm}$ tumor thickness was a worse prognostic factor. ${ }^{33}$ Both of these observations are in contrast with our findings, in which a tumor thickness of even $2 \mathrm{~mm}$ proves to be significantly associated with lymph node metastasis. So, the relationship between tumor thickness and neck nodal metastasis should not be considered questionable; rather, the size of tumor thickness is the subject of debate.

While considering the outcomes of patients, Janot et $\mathrm{al}^{34}$ and Kantola et $\mathrm{al}^{35}$ found an association between the patients' age and poor outcomes, which was something also observed in our study. Further on, it was also noted that an increase in age is associated with an increased risk of cervical lymph node metastasis.

Very little has been done to explore the predictors of cervical neck node metastasis, with respect to tumor thickness, from our part of the world. There is limited local literature regarding the subject. With buccal mucosa tumors forming a very high proportion of oral cavity squamous cell carcinoma in our region, and having an unexpectedly high aggressive behavior, we believed that the predictors of occult cervical lymph node metastasis would be worthy of research.

Our study showed that tumor thickness is significantly associated with the presence of lymph node metastasis in the univariate and the multivariate analyses $(p<0.05)$. The association between tumor thickness and lymph node metastasis has been well demonstrated. However, there has been a lack of homogeneity in terms of study population and site of the primary tumor. We were also able to demonstrate that a tumor thickness of $2 \mathrm{~mm}$ or more favors an elective neck dissection where squamous cell carcinoma of the buccal mucosa is concerned.

Tumor thickness significantly influences the survival of the patients, as reported in Gonzalez-Moles et al, Brown et al and Spiro et al. ${ }^{36-38}$ As an increase in tumor thickness reduces the survival rates among the patients, the causal relationship between tumor thickness and neck node metastasis in buccal squamous cell carcinoma needs to be explored, and further prospective studies with larger sample sizes and longer follow-up (up to 10 years) periods are required to unify the criteria for the measurement of this important prognostic factor.

\section{Conclusion}

We conclude that tumor thickness is significantly related to neck nodal metastasis in buccal squamous cell carcinoma, considering the age of the patient and the size of the tumor.

\section{References}

1 Mignogna MD, Fedele S, Lo Russo L. The World Cancer Report and the burden of oral cancer. Eur J Cancer Prev 2004;13(02):139-142

2 Musani MA, Jawed I, Marfani S, Khambaty Y, Jalisi M, Khan SA. Carcinoma cheek: regional pattern and management. J Ayub Med Coll Abbottabad 2009;21(03):87-91
3 Mamelle G, Pampurik J, Luboinski B, Lancar R, Lusinchi A, Bosq J. Lymph node prognostic factors in head and neck squamous cell carcinomas. Am J Surg 1994;168(05):494-498

4 Huang SH, Hwang D, Lockwood G, Goldstein DP, O'Sullivan B. Predictive value of tumor thickness for cervical lymph-node involvement in squamous cell carcinoma of the oral cavity: a metaanalysis of reported studies. Cancer 2009;115(07):1489-1497

5 Pentenero M, Gandolfo S, Carrozzo M. Importance of tumor thickness and depth of invasion in nodal involvement and prognosis of oral squamous cell carcinoma: a review of the literature. Head Neck 2005;27(12):1080-1091

6 Cheng A, Schmidt BL. Management of the NO neck in oral squamous cell carcinoma. Oral Maxillofac Surg Clin North Am 2008;20(03):477-497

7 Dünne AA, Folz BJ, Kuropkat C, Werner JA. Extent of surgical intervention in case of NO neck in head and neck cancer patients: an analysis of data collection of 39 hospitals. Eur Arch Otorhinolaryngol 2004;261(06):295-303

8 Werning JW, Heard D, Pagano C, Khuder S. Elective management of the clinically negative neck by otolaryngologists in patients with oral tongue cancer. Arch Otolaryngol Head Neck Surg 2003; 129(01):83-88

9 Capote A, Escorial V, Muñoz-Guerra MF, Rodríguez-Campo FJ, Gamallo C, Naval L. Elective neck dissection in early-stage oral squamous cell carcinoma-does it influence recurrence and survival? Head Neck 2007;29(01):3-11

10 Okada Y, Mataga I, Katagiri M, Ishii K. An analysis of cervical lymph nodes metastasis in oral squamous cell carcinoma. Relationship between grade of histopathological malignancy and lymph nodes metastasis. Int J Oral Maxillofac Surg 2003;32(03):284-288

11 Pimenta Amaral TM, Da Silva Freire AR, Carvalho AL, Pinto CA, Kowalski LP. Predictive factors of occult metastasis and prognosis of clinical stages I and II squamous cell carcinoma of the tongue and floor of the mouth. Oral Oncol 2004;40(08):780-786

12 Alkureishi LW, Ross GL, Shoaib T, et al. Does tumor depth affect nodal upstaging in squamous cell carcinoma of the head and neck? Laryngoscope 2008;118(04):629-634

13 Clark JR, Naranjo N, Franklin JH, de Almeida J, Gullane PJ. Established prognostic variables in NO oral carcinoma. Otolaryngol Head Neck Surg 2006;135(05):748-753

14 Jing J, Li L, He W, Sun G. Prognostic predictors of squamous cell carcinoma of the buccal mucosa with negative surgical margins. J Oral Maxillofac Surg 2006;64(06):896-901

15 Sheahan P, O'Keane C, Sheahan JN, O'Dwyer TP. Effect of tumour thickness and other factors on the risk of regional disease and treatment of the NO neck in early oral squamous carcinoma. Clin Otolaryngol Allied Sci 2003;28(05):461-471

16 Kane SV, Gupta M, Kakade AC, D' Cruz A. Depth of invasion is the most significant histological predictor of subclinical cervical lymph node metastasis in early squamous carcinomas of the oral cavity. Eur J Surg Oncol 2006;32(07):795-803

17 Moore C, Kuhns JG, Greenberg RA. Thickness as prognostic aid in upper aerodigestive tract cancer. Arch Surg 1986;121(12): 1410-1414

18 Hanif M, Zaidi P, Kamal S, Hameed A. Institution-based cancer incidence in a local population in Pakistan: nine year data analysis. Asian Pac J Cancer Prev 2009;10(02):227-230

19 Bhurgri Y, Bhurgri A, Usman A, et al. Epidemiological review of head and neck cancers in Karachi. Asian Pac J Cancer Prev 2006; 7(02):195-200

20 Diaz EM Jr, Holsinger FC, Zuniga ER, Roberts DB, Sorensen DM. Squamous cell carcinoma of the buccal mucosa: one institution's experience with 119 previously untreated patients. Head Neck 2003;25(04):267-273

21 Lin CS, Jen YM, Cheng MF, et al. Squamous cell carcinoma of the buccal mucosa: an aggressive cancer requiring multimodality treatment. Head Neck 2006;28(02):150-157 
22 Sieczka E, Datta R, Singh A, et al. Cancer of the buccal mucosa: are margins and T-stage accurate predictors of local control? Am J Otolaryngol 2001;22(06):395-399

23 Shaw RJ, McGlashan G, Woolgar JA, et al. Prognostic importance of site in squamous cell carcinoma of the buccal mucosa. Br J Oral Maxillofac Surg 2009;47(05):356-359

24 Ferlito A, Rinaldo A, Devaney KO, et al. Prognostic significance of microscopic and macroscopic extracapsular spread from metastatic tumor in the cervical lymph nodes. Oral Oncol 2002;38(08): 747-751

25 Larsen SR, Johansen J, Sørensen JA, Krogdahl A. The prognostic significance of histological features in oral squamous cell carcinoma. J Oral Pathol Med 2009;38(08):657-662

26 Warburton G, Nikitakis NG, Roberson P, et al. Histopathological and lymphangiogenic parameters in relation to lymph node metastasis in early stage oral squamous cell carcinoma. J Oral Maxillofac Surg 2007;65(03):475-484

27 Barrera JE, Miller ME, Said S, Jafek BW, Campana JP, Shroyer KR. Detection of occult cervical micrometastases in patients with head and neck squamous cell cancer. Laryngoscope 2003;113(05):892-896

28 Enepekides DJ, Sultanem K, Nguyen C, Shenouda G, Black MJ, Rochon L. Occult cervical metastases: immunoperoxidase analysis of the pathologically negative neck. Otolaryngol Head Neck Surg 1999;120(05):713-717

29 Yoshida K, Kashima K, Suenaga S, Nomi N, Shuto J, Suzuki M. Immunohistochemical detection of cervical lymph node micrometastases from T2N0 tongue cancer. Acta Otolaryngol 2005; 125(06):654-658
30 Akoğlu E, Dutipek M, Bekiş R, Değirmenci B, Ada E, Güneri A. Assessment of cervical lymph node metastasis with different imaging methods in patients with head and neck squamous cell carcinoma. J Otolaryngol 2005;34(06):384-394

31 Merritt RM, Williams MF, James TH, Porubsky ES. Detection of cervical metastasis. A meta-analysis comparing computed tomography with physical examination. Arch Otolaryngol Head Neck Surg 1997;123(02):149-152

32 Mishra RC, Parida G, Mishra TK, Mohanty S. Tumour thickness and relationship to locoregional failure in cancer of the buccal mucosa. Eur J Surg Oncol 1999;25(02):186-189

33 Urist MM, O'Brien CJ, Soong SJ, Visscher DW, Maddox WA. Squamous cell carcinoma of the buccal mucosa: analysis of prognostic factors. Am J Surg 1987;154(04):411-414

34 Janot F, Klijanienko J, Russo A, et al. Prognostic value of clinicopathological parameters in head and neck squamous cell carcinoma: a prospective analysis. Br J Cancer 1996;73(04):531-538

35 Kantola S, Parikka M, Jokinen K, et al. Prognostic factors in tongue cancer - relative importance of demographic, clinical and histopathological factors. Br J Cancer 2000;83(05):614-619

36 Gonzalez-Moles MA, Esteban F, Rodriguez-Archilla A, Ruiz-Avila I, Gonzalez-Moles S. Importance of tumour thickness measurement in prognosis of tongue cancer. Oral Oncol 2002;38(04):394-397

37 Brown B, Barnes L, Mazariegos J, Taylor F, Johnson J, Wagner RL. Prognostic factors in mobile tongue and floor of mouth carcinoma. Cancer 1989;64(06):1195-1202

38 SpiroRH,HuvosAG,WongGY,SpiroJD,GneccoCA,StrongEW.Predictive valueoftumorthicknessinsquamouscarcinomaconfinedtothetongue andfloorofthemouth.AmJSurg1986;152(04):345-350 